\title{
ANALYSIS OF A SEMI-BATCH REACTOR FOR CONTROL PURPOSES
}

\author{
František Gazdoš and Lubomír Macků \\ Faculty of Applied Informatics \\ Tomas Bata University in Zlín \\ Nad stráněmi 4511, 760 05, Zlín, Czech Republic \\ E-mail: gazdos@fai.utb.cz
}

\begin{abstract}
KEYWORDS
Exothermic Semi-batch Reactor, Chromium Waste, Modelling, Analysis, Simulation.
\end{abstract}

\begin{abstract}
The paper presents a control system design oriented analysis of a semi-batch reactor used for tanning waste recovery. The analysis is performed with the help of modelling and simulation means and provides useful information for optimal control design of the process.
\end{abstract}

\section{INTRODUCTION}

The tannery is an essential industry process today. Its product is a natural hide. Some of the leather properties (such as softness, plasticity, stability, absorption) cannot be replaced by any artificial material.

There are a lot of technological operations during the leather-to-hide conversion, starting with washing, continuing by tanning etc. These are usually connected with huge water, energy and chemicals consumption resulting in negative impact on the environment. Recently, one of the very fundamental operations is chromium salt tanning. It is possible to obtain only 200 [kg] of hide from 1000 [kg] of leather, but over 600 $[\mathrm{kg}]$ of solid waste originates from this process; the rest is drained away in the form of liquid waste during the chromium salt tanning process. The USA produces almost 60000 tons of this solid waste and the worldwide production is approximately 10 times bigger (Cabeza et al. 1998). Currently, majority of this solid waste is land filled. It can result in leakage of $\mathrm{Cr} 3+$ into groundwater. After oxidation, for example in sewage treatment plants during purification from unhealthy bacteria, the $\mathrm{Cr} 3+$ to $\mathrm{Cr} 6+$ conversion can occur. The Cr6+ compounds belong to cancerous substances so they are dangerous to health. As a consequence, at present, alternative methods of dealing with the chromium waste are sought and investigated (Aloy and Vulliermet 1998; Tiravanti et al. 1996, 1997). The enzymatic hydrolysis is one of the considered alternatives (Kolomazník et al. 1996). This technique separates the chrome from protein in the form of the chromium filter cake. All products of this process are usable - it is a waste-free technology.

This paper deals with an analysis of a chemical reactor for chromium sludge (chromium filter cake) recovery. The reactor is used for the enzymatic hydrolysis and the analysis is performed from the control theory point of view by simulation means mainly to obtain useful information for subsequent optimal control design.

The contribution is structured as follows: after the introduction, a detailed description of the reactor follows. In the next sections, a mathematical model of the system is derived and all variables are defined together with their physical values and limits. Further, steady-state and dynamical behaviour is studied by simulation means. A detailed analysis of the reactor from the systems theory point of view follows in next sections, giving useful information for optimal control design. Possible control strategies are discussed at the end of the contribution together with areas for possible future research.

\section{A SEMI-BATCH REACTOR}

The chromium sludge is processed in a chemical reactor sketched in Fig.1. by an exothermic chemical reaction with chrome sulphate acid. During this reaction a considerable quantity of heat is developing so that control of the reaction is necessary.

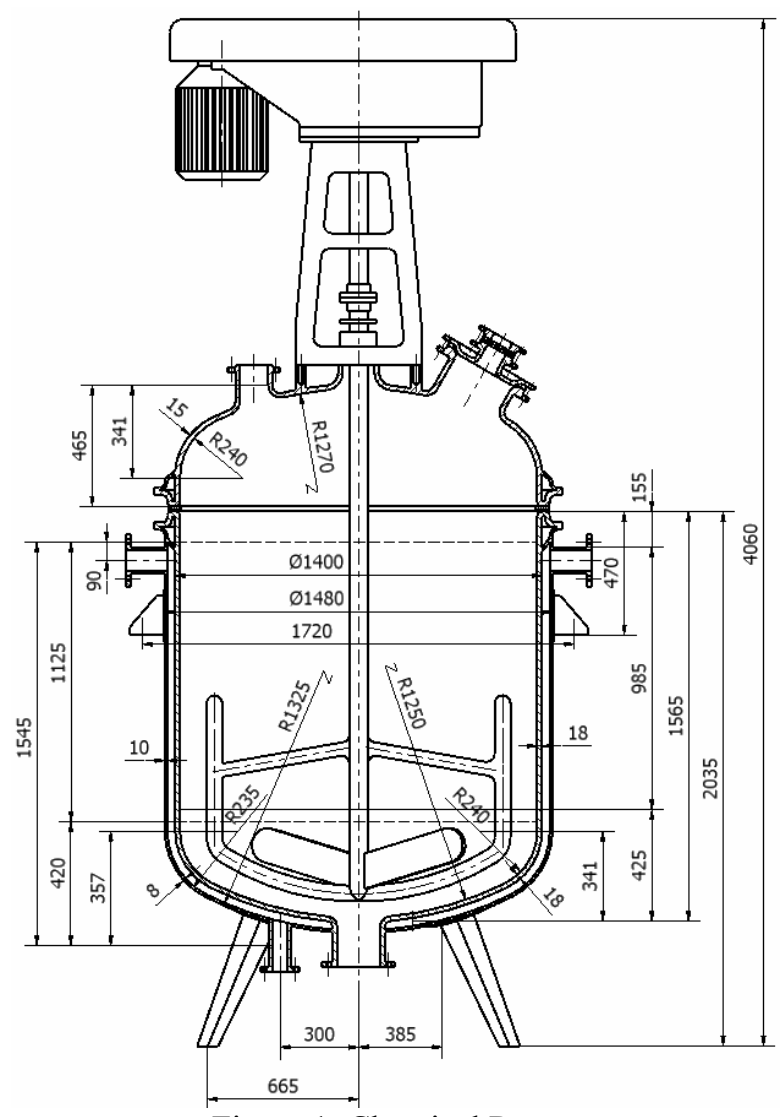

Figure 1: Chemical Reactor 


\section{System description}

In order to investigate main properties of the real process, a mathematical model of the chemical reactor was derived based on Fig. 2 .

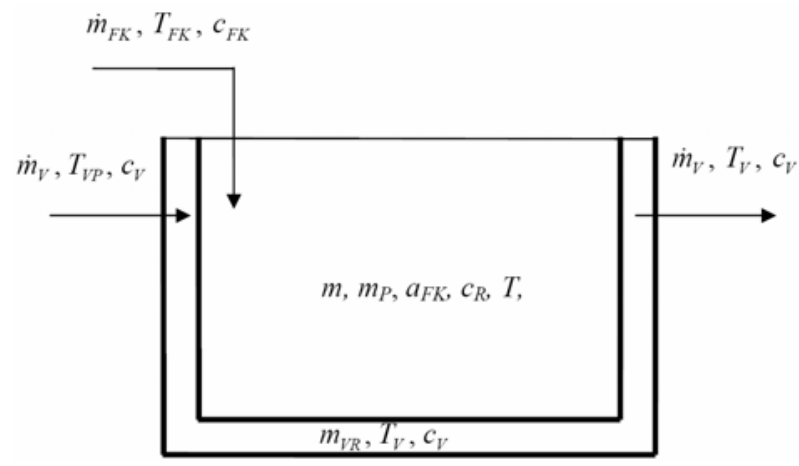

Figure 2: Chemical Reactor Scheme

The scheme above shows a chemical semi-batch reactor with initial filling $m_{\mathrm{P}}[\mathrm{kg}]$ given by the solution of chemicals without the chromium sludge (filter cake). This is fed into the reactor by $\dot{m}_{F K}[\mathrm{~kg} / \mathrm{s}]$ to control the developing heat since the temperature has to stay under a certain critical level $\left(T(t) \prec 100^{\circ} \mathrm{C}\right)$, otherwise the reactor could be destroyed. On the other hand it is desirable to utilise the maximum capacity of the reactor to process the maximum amount of waste in the shortest possible time (higher temperature is desirable). Therefore an optimal control strategy has to find a trade-off between these opposite requirements.

\section{Mathematical model}

Under usual simplifications, based on the mass and heat balance, the following 4 nonlinear ordinary differential equations can be derived (Macků 2005, 2004):

$$
\begin{gathered}
\dot{m}_{F K}=\frac{d}{d t} m(t) \\
\dot{m}_{F K}=k m(t) a_{F K}(t)+\frac{d}{d t}\left[m(t) a_{F K}(t)\right] \\
\dot{m}_{F K} c_{F K} T_{F K}+\Delta H_{r} k m(t) a_{F K}(t)= \\
=K S\left[T(t)-T_{v}(t)\right]+\frac{d}{d t}\left[m(t) c_{R} T(t)\right] \\
\dot{m}_{v} c_{v} T_{v p}+K S\left[T(t)-T_{v}(t)\right]=\dot{m}_{v} c_{v} T_{v}(t)+m_{v R} c_{v} \frac{d}{d t} T_{v}(t)
\end{gathered}
$$

The first equation expresses the total mass balance of the chemical solution in the reactor. The symbol $\dot{m}_{F K}\left[\mathrm{~kg} . \mathrm{s}^{-1}\right]$ expresses the mass flow of the entering chromium sludge and $m^{\prime}(t)\left[\mathrm{kg} . \mathrm{s}^{-1}\right]$ describes the accumulation of the in-reactor content.

The second equation represents the chromium sludge mass balance. The input is $\dot{m}_{F K}\left[\mathrm{~kg} \cdot \mathrm{s}^{-1}\right]$ again, the accumulation is given by the last term $\left[m(t) a_{F K}(t)\right]^{\prime}\left[\mathrm{kg} . \mathrm{s}^{-1}\right]$, where $a_{F K}(t)[-]$ denotes the mass concentration of the chromium sludge in the reactor and $m(t)[\mathrm{kg}]$ describes weight of the reaction components in the system. The expression $k m(t) a_{F K}(t)\left[\mathrm{kg} \cdot \mathrm{s}^{-1}\right]$ defines the chromium sludge extinction by the chemical reaction. Here, $k\left[\mathrm{~s}^{-1}\right]$ is the reaction rate constant expressed by the Arrhenius equation (2) where $A\left[\mathrm{~s}^{-1}\right], E\left[\mathrm{~J} \cdot \mathrm{mol}^{-1}\right]$ and $R\left[\mathrm{~J} \cdot \mathrm{mol}^{-}\right.$ $\left.{ }^{1} \cdot \mathrm{K}^{-1}\right]$ are pre-exponential factor, activation energy and gas constant respectively.

$$
k=A e^{-\frac{E}{R T(t)}}
$$

The third equation describes the enthalpy balance. The input heat entering the reactor in the form of the chromium sludge is expressed by the term $\dot{m}_{F K} c_{F K} T_{F K}$, the heat arising from the chemical reaction is given by the expression $\Delta H_{r} k m(t) a_{F K}(t)$ and the heat transmission through the reactor wall is expressed by the formula $K S\left[T(t)-T_{v}(t)\right]$. The individual symbols used above mean: $c_{F K}\left[\mathrm{~J}_{\mathrm{kg}} \mathrm{kg}^{-1} \cdot \mathrm{K}^{-1}\right]-$ chromium sludge specific heat capacity, $c_{R}\left[\mathrm{~J}_{\mathrm{kg}}^{-1} \cdot \mathrm{K}^{-1}\right]-$ specific heat capacity of the reactor content, $T_{F K}[\mathrm{~K}]-$ chromium sludge temperature, $\Delta H_{r}\left[\mathrm{~J}_{\mathrm{kg}} \mathrm{kg}^{-1}\right]$ - reaction heat, $K$ $\left[\mathrm{J} \cdot \mathrm{m}^{-2} \cdot \mathrm{K}^{-1} \cdot \mathrm{s}^{-1}\right]$ - conduction coefficient, $S\left[\mathrm{~m}^{2}\right]$ - heat transfer surface, $T(t)[\mathrm{K}]$ - temperature of reaction components in the reactor, $T_{v}(t)[\mathrm{K}]-$ temperature of a coolant in the reactor double wall.

The last equation describes coolant heat balance. The input heat is given by $\dot{m}_{v} c_{v} T_{v p}$, the heat entering the coolant by the reactor wall is expressed by $K S\left[T(t)-T_{v}(t)\right]$, the heat going out with the coolant is described as $\dot{m}_{v} c_{v} T_{v}(t)$ and the heat accumulated in the double wall describes the last term $m_{v R} c_{v} T_{V}^{\prime}(t)$. The symbols mean: $\dot{m}_{v}\left[\mathrm{~kg} . \mathrm{s}^{-1}\right]-$ coolant mass flow, $c_{v}$ $\left[\mathrm{J} \mathrm{kg}^{-1} \cdot \mathrm{K}^{-1}\right]-$ coolant specific heat capacity, $T_{v p}[\mathrm{~K}]-$ input coolant temperature, $m_{v R}[\mathrm{~kg}]$ - coolant mass weight in the reactor double wall.

Variables $\dot{m}_{F K}, \dot{m}_{v}, T_{F K}, T_{v p}$ are manipulated signals, however, from practical point of view, only $\dot{m}_{F K}$ and $\dot{m}_{v}$ are usable. The temperature change of $T_{F K}$ or $T_{v p}$ is inconvenient due to the economic reasons (great energy demands).

For simulation purposes, the following values of the constants used in the mathematical model (1) were adopted (obtained analytically, experimentally, estimated or taken from the literature, for details see Macků 2004): $A=219.6 \mathrm{~s}^{-1}, E=29968 \mathrm{~J} \cdot \mathrm{mol}^{-1}, R=$ $8.314 \mathrm{~J} . \mathrm{mol}^{-1} \cdot \mathrm{K}^{-1}, c_{F K}=4400 \mathrm{~J} \cdot \mathrm{kg}^{-1} \cdot \mathrm{K}^{-1}, c_{v}=4118$ 
$\mathrm{J} . \mathrm{kg}^{-1} \cdot \mathrm{K}^{-1}, c_{R}=4500 \mathrm{~J} \cdot \mathrm{kg}^{-1} \cdot \mathrm{K}^{-1}, m_{v R}=220 \mathrm{~kg}, \Delta H_{r}=$ $1392350 \mathrm{~J} \cdot \mathrm{kg}^{-1}, K=200 \mathrm{~J} \cdot \mathrm{m}^{-2} \cdot \mathrm{K}^{-1} \cdot \mathrm{s}^{-1}, S=7.36 \mathrm{~m}^{2}$, $\dot{m}_{v}=1 \mathrm{~kg} \cdot \mathrm{s}^{-1}, T_{F K}=293.15 \mathrm{~K}=20^{\circ} \mathrm{C}, T_{v p}=288.15 \mathrm{~K}$ $=15^{\circ} \mathrm{C}$. The $\dot{m}_{F K}$ feeding varied from 0 to $3 \mathrm{~kg} \cdot \mathrm{s}^{-1}$. Initial conditions were defined as: $m(0)=m_{p}=1810 \mathrm{~kg} \quad$ (initial reactor filling), $a_{F K}(0)=0$ (initial mass concentration of the chromium sludge in the reactor), $T(0)=323.15 \mathrm{~K}=$ $50^{\circ} \mathrm{C}$ (initial temperature of the reactor filling) and initial coolant temperature $T_{v}(0)=293.15 \mathrm{~K}=20^{\circ} \mathrm{C}$.

\section{Technological limits and variables saturation}

Maximum filling of the reactor is limited by its volume to the value of $m<2450 \mathrm{~kg}$ approximately. Then the process of feeding by the chromium sludge $\dot{m}_{F K}$ has to be stopped. The feeding can be practically realized in the range $\dot{m}_{F K} \in\langle 0 ; 3\rangle \mathrm{kg} . \mathrm{s}^{-1}$. As stated in the system description, the temperature cannot exceed the limit $T(t) \prec 100^{\circ} \mathrm{C}$; this holds also for the coolant (water) but it is not so critical in this case as shown by the further experiments.

\section{SIMULATION ANALYSIS}

In order to prepare a convenient control strategy for the process described above, first a steady-state and dynamic analyses were performed with the help of simulation means.

\section{Steady-state analysis}

The reactor described above, i.e. a semi-batch reactor, has only one steady state given by:

$$
\dot{m}_{F K}=0 ; \quad a_{F K}=0 ; \quad T=T_{v}=T_{v p}
$$

It means that the steady state can occur only at the beginning of the process (before feeding the reactor) or at the end of the reaction running inside.

\section{Dynamics analysis}

Dynamical behaviour analysis of a system is also an important part in the control design process. It gives insight into stability and other important properties of the system, such as time-constants, gains and nonminimum-phase behaviour. Using simulation means (MATLAB/Simulink), the following graphs were recorded as a step-responses of the input variable $\dot{m}_{F K}$ (other variables were kept at their operating values defined previously). The input variable was chosen in the range: $\dot{m}_{F K}=\left[\begin{array}{lllll}0.05 & 0.1 & 0.5 & 1 & 3\end{array}\right]\left[\mathrm{kg} \cdot \mathrm{s}^{-1}\right]$.

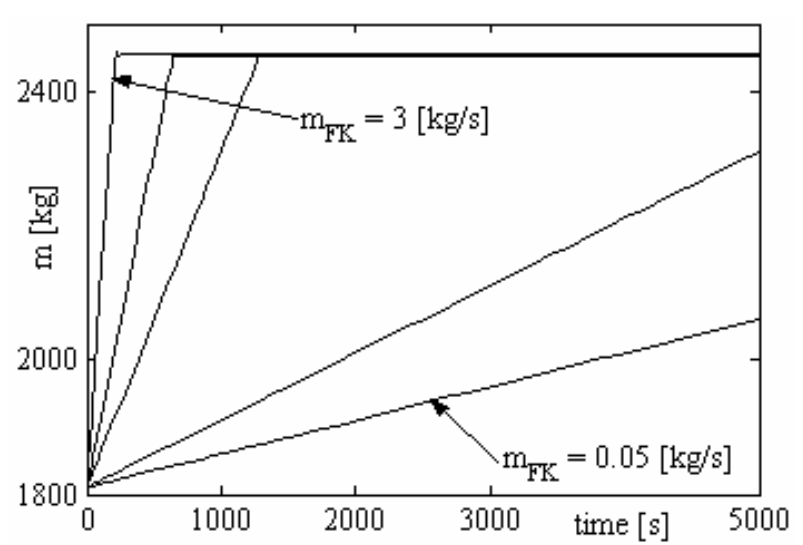

Figure 3: Total Mass Response

The figure above shows increase of the total mass in the reactor for various input flow rates of the chromium sludge. The simulation reveals integrating, astatic behaviour and it already respects the limitations introduced previously (max. mass in the reactor $m_{\max }=2450[\mathrm{~kg}]$ ).

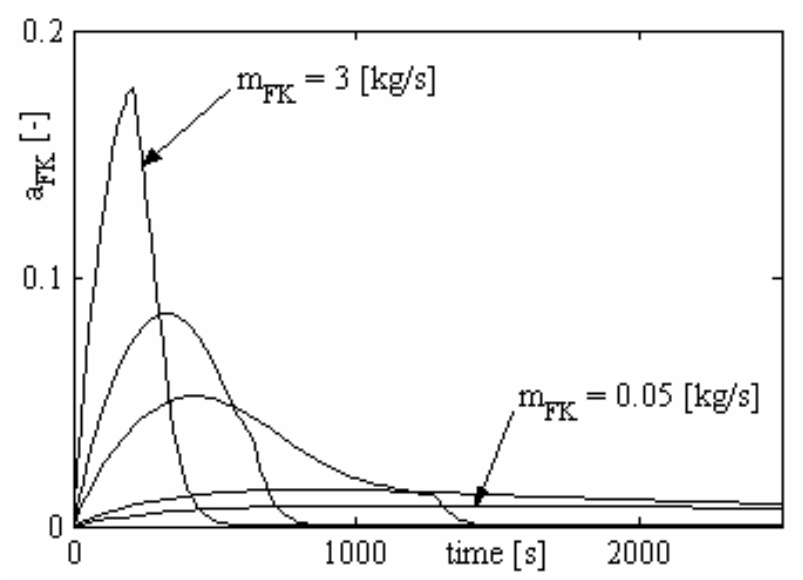

Figure 4: Chromium Sludge Mass Concentration Response

The response presented in Fig. 4 reveals derivative behaviour of the variable $a_{F K}(t)$ for various values of $\dot{m}_{F K}$.

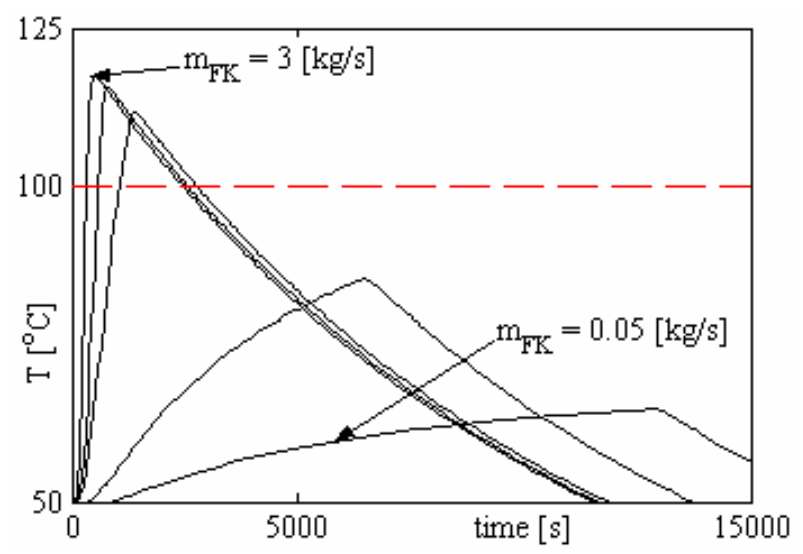

Figure 5: Temperature-in-the-Reactor Response 
The response of Fig. 5 shows temperature increase inside the reactor - it can be seen how the temperature rises as a result of the chemical reaction. The faster input flow rate of the chromium sludge, the faster reaction and temperature increase. Then, the next increase is limited by the restriction on the maximum possible mass in the reactor followed by gradual temperature fall. From the graph it is also clear that for the simulated range of $\dot{m}_{F K}$ the temperature goes beyond the allowed limit $T(t) \prec 100\left[{ }^{\circ} \mathrm{C}\right]$ for higher $\dot{m}_{F K}$-values, therefore the process needs to be controlled properly.

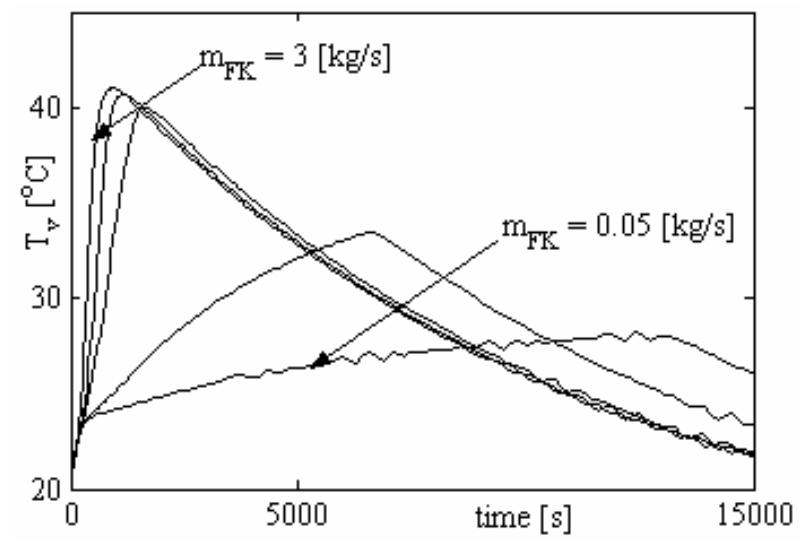

Figure 6: Coolant Temperature Response

A record of the coolant temperature is presented in Fig. 6. As can be seen from the graph, the temperature of the media for the whole range of $\dot{m}_{F K}$ is not critical since water is used for the cooling (provided the defined flow rate $\dot{m}_{v}=1[\mathrm{~kg} / \mathrm{s}]$ is ensured).

\section{CONTROL THEORY POINT OF VIEW}

From the systems theory point of view the reactor has four input signals $\dot{m}_{F K}(t), \dot{m}_{v}(t), T_{F K}(t)$ and $T_{v p}(t)$, four state variables $m(t), a_{F K}(t), T(t), T_{v}(t)$ and one output signal to be controlled given by the temperature inside the reactor $T(t)$. Hence, it can be generally seen as a Multi Input - Multi Output (MIMO) system of $4^{\text {th }}$ order. In addition it possesses strongly nonlinear behaviour. Practically, the only manipulated variables are input flow rates of the chromium sludge $\dot{m}_{F K}(t)$ and of the coolant $\dot{m}_{v}(t)$. Therefore, input temperatures of the filter cake $T_{F K}(t)$ and of the coolant $T_{v p}(t)$ can be alternatively seen as disturbances. For further analysis, the reactor model described by the system of differential equations (1) is transformed into a linear time-variant (LTV) system.

\section{Linear model}

Having generally a nonlinear model defined by a system of formulas

$$
\boldsymbol{x}^{\prime}(t)=\boldsymbol{f}[t, \boldsymbol{x}(t), \boldsymbol{u}(t)]
$$

where $\boldsymbol{x}(t)$ defines a vector of state-variables $\left[\begin{array}{llll}x_{1}(t) & x_{2}(t) & \cdots & x_{n}(t)\end{array}\right], \quad \boldsymbol{u}(t)$ vector of input variables $\left[\begin{array}{llll}u_{1}(t) & u_{2}(t) & \cdots & u_{m}(t)\end{array}\right]$ and $\boldsymbol{f}$ is a nonlinear vector function $\left[\begin{array}{llll}f_{1} & f_{2} & \cdots & f_{n}\end{array}\right]$, then the linear model in a given operating (steady-state) point $\left(\boldsymbol{u}^{s}, \boldsymbol{y}^{s}\right)$ can be generally obtained using formulae:

$$
\boldsymbol{x}^{\prime}(t)=\boldsymbol{A} \boldsymbol{x}(t)+\boldsymbol{B} \boldsymbol{u}(t)
$$

with constant matrices $\boldsymbol{A}, \boldsymbol{B}$ calculated as:

$$
\begin{gathered}
\boldsymbol{A}=\left[\begin{array}{cccc}
\frac{\partial f_{1}}{\partial x_{1}} & \frac{\partial f_{1}}{\partial x_{2}} & \cdots & \frac{\partial f_{1}}{\partial x_{n}} \\
\frac{\partial f_{2}}{\partial x_{1}} & \frac{\partial f_{2}}{\partial x_{2}} & \cdots & \frac{\partial f_{2}}{\partial x_{n}} \\
\vdots & \vdots & \vdots & \vdots \\
\frac{\partial f_{n}}{\partial x_{1}} & \frac{\partial f_{n}}{\partial x_{2}} & \cdots & \frac{\partial f_{n}}{\partial x_{n}}
\end{array}\right]_{\boldsymbol{x}=\boldsymbol{x}^{s}} \\
\boldsymbol{B}=\left[\begin{array}{cccc}
\frac{\partial f_{1}}{\partial u_{1}} & \frac{\partial f_{1}}{\partial u_{2}} & \cdots & \frac{\partial f_{1}}{\partial u_{m}} \\
\frac{\partial f_{2}}{\partial u_{1}} & \frac{\partial f_{2}}{\partial u_{2}} & \cdots & \frac{\partial f_{2}}{\partial u_{m}} \\
\vdots & \vdots & \vdots & \vdots \\
\frac{\partial f_{n}}{\partial u_{1}} & \frac{\partial f_{n}}{\partial u_{2}} & \cdots & \frac{\partial f_{n}}{\partial u_{m}}
\end{array}\right]_{\boldsymbol{u}=\boldsymbol{u}}
\end{gathered}
$$

As the reactor embodies astatic behaviour, it is not possible to compute the matrices in a chosen (steadystate) operating point. However, the linearization can be performed generally, resulting in a time-variant system:

$$
\boldsymbol{x}^{\prime}(t)=\boldsymbol{A}(t) \boldsymbol{x}(t)+\boldsymbol{B}(t) \boldsymbol{u}(t)
$$

where the matrices $\boldsymbol{A}(t), \boldsymbol{B}(t)$ are no longer constant but time-dependent. Using the formulas above, the originally nonlinear model of the reactor has been transformed into a linear time-variant model with the matrices $\boldsymbol{A}(t), \boldsymbol{B}(t)$ of the form (8), 


$$
\begin{gathered}
\boldsymbol{A}(t)=\left[\begin{array}{cccc}
0 & 0 & 0 & 0 \\
a_{21}(t) & a_{22}(t) & a_{23}(t) & 0 \\
a_{31}(t) & a_{32}(t) & a_{33}(t) & a_{34}(t) \\
0 & 0 & a_{43} & a_{44}(t)
\end{array}\right] \\
\boldsymbol{B}(t)=\left[\begin{array}{cccc}
1 & 0 & 0 & 0 \\
b_{21}(t) & 0 & 0 & 0 \\
b_{31}(t) & 0 & b_{33}(t) & 0 \\
0 & b_{42}(t) & 0 & b_{44}(t)
\end{array}\right]
\end{gathered}
$$

where the particular ralations describing the coefficients (except for $a_{43}$ all coefficients are time-dependent) are presented in the appendix. Generally, output from a linear system is defined as:

$$
\boldsymbol{y}(t)=\boldsymbol{C x}(t)+\boldsymbol{D} \boldsymbol{u}(t)
$$

with matrices $\boldsymbol{C}, \boldsymbol{D}$ defined in our case as:

$$
\boldsymbol{C}=\left[\begin{array}{llll}
0 & 0 & 1 & 0
\end{array}\right], \boldsymbol{D}=\left[\begin{array}{llll}
0 & 0 & 0 & 0
\end{array}\right]
$$

(output for control purposes is only the temperature inside the reactor and the system is strictly proper).

\section{Transfer function}

If we have the matrices $\boldsymbol{A}, \boldsymbol{B}, \boldsymbol{C}, \boldsymbol{D}$ of a linear (or linearized) model then it is possible to compute a transfer function (matrix in a MIMO case) of a system, which is a useful relation for control system analysis and design. It gives insight into input-output behaviour of the system variables and provides useful information, such as stability, non-minimum-phase behaviour, timeconstants, gain etc. For constant matrices mentioned above, it can be computed simply as:

$$
\boldsymbol{G}(s)=\boldsymbol{C}\left(s \boldsymbol{I}_{n}-\boldsymbol{A}\right)^{-1} \boldsymbol{B},
$$

where $s$ is the complex Laplace variable and $\boldsymbol{I}_{n}$ is the $n$-by- $n$ identity matrix. As the reactor analyzed in this contribution is astatatic, the linearized model is timedependent and the "proper" transfer function introduced above cannot be computed. However, in a given timemoment $t$, the time-dependent matrices $\boldsymbol{A}(t), \boldsymbol{B}(t)$ can be considered constant, i.e. it is possible to compute a "pseudo" transfer function (t.f.) describing instantaneous relation between the output and input signals. Then this "pseudo" transfer function is also time-dependent, but for a given time-moment it yields instantaneous transfer function of the system:

$$
\tilde{\boldsymbol{G}}(s, t)=\boldsymbol{C}\left(s \boldsymbol{I}_{n}-\boldsymbol{A}(t)\right)^{-1} \boldsymbol{B}(t) .
$$

Using this idea and the relations (8)-(10) it is possible to compute a "pseudo" transfer function of the reactor.
Since the system generally has one output $T(t)$ and 4 inputs $\dot{m}_{F K}(t), \dot{m}_{v}(t), T_{F K}(t), T_{v p}(t)$, the resultant t.f. is a vector of the 1-by-4 size:

$$
\tilde{\boldsymbol{G}}=\left[\begin{array}{llll}
G_{T / \dot{m}_{F K}} & G_{T / \dot{m}_{v}} & G_{T / T_{F K}} & G_{T / T_{v p}}
\end{array}\right] .
$$

The first term $G_{T / \dot{m}_{F K}}$ describes the relation between the temperature inside the reactor $T(t)$ and the input flow rate of the chromium sludge $\dot{m}_{F K}(t)$. The other terms describes the relations between the temperature and the variables $\dot{m}_{v}(t), T_{F K}(t), T_{v p}(t)$ respectively. As stated earlier, the only practically manipulated variables are $\dot{m}_{F K}(t)$ and $\dot{m}_{v}(t)$. Therefore, next analysis is focused on the relation between these variables and the inner reactor temperature. The "pseudo" transfer function for these two input variables have these general forms (using (8)-(10) and (12)):

$$
\begin{gathered}
G_{T / \dot{m}_{F K}}(s, t)=\frac{B_{3}(t) s^{3}+B_{2}(t) s^{2}+B_{1}(t) s+B_{0}(t)}{s\left(s^{3}+A_{2}(t) s^{2}+A_{1}(t) s+A_{0}(t)\right)}, \\
G_{T / \dot{m}_{v}}(s, t)=\frac{B_{1}^{\prime}(t) s+B_{0}^{\prime}(t)}{s^{3}+A_{2}(t) s^{2}+A_{1}(t) s+A_{0}(t)},
\end{gathered}
$$

where relations for the time-dependent coefficients $A_{i}(t), B_{i}(t)$ are given in the appendix (due to the limited space, for information only formulas concerning the most important t.f. $G_{T / \dot{m}_{F K}}$ are presented).

From the equations presented above, it can be seen that the relation between $T(t)$ and $\dot{m}_{F K}(t)$ is generally integrative whereas between $T(t)$ and $\dot{m}_{v}(t)$ only proportional. At present, the only practically manipulated variable is $\dot{m}_{F K}(t)$, therefore, the further investigation is focused on the analysis of the transfer function $G_{T / \dot{m}_{F K}}$. Although it would be also useful to investigate also $G_{T / \dot{m}_{v}}$, due to the limited space of this paper, this analysis is not provided.

\section{Transfer function coefficients range}

In order to determine the range of $G_{T / \dot{m}_{F K}}$ coefficients, a series of simulation experiments were performed in the MATLAB/Simulink environment. The variable $\dot{m}_{F K}(t)$ was changing in the admissible range from 0 to $3[\mathrm{~kg} / \mathrm{s}]$ with the step 0.1 and both maximum and minimum values of the $G_{T / \dot{m}_{F K}}$ coefficients were recorded. Summary of the achieved results is presented in Table 1. 
Table 1: Range of $G_{T / \dot{m}_{F K}}$ Coefficients

\begin{tabular}{|c|c|c|}
\hline Coefficient & Minimum value & Maximum value \\
\hline$B_{3}$ & -0.0426 & $-8.632 \times 10^{-4}$ \\
\hline$B_{2}$ & $9.944 \times 10^{-5}$ & 0.0016 \\
\hline$B_{1}$ & $5.221 \times 10^{-7}$ & $1.022 \times 10^{-5}$ \\
\hline$B_{0}$ & $-1.220 \times 10^{-8}$ & $5.810 \times 10^{-11}$ \\
\hline$A_{2}$ & 0.0051 & 0.0301 \\
\hline$A_{1}$ & $-8.777 \times 10^{-6}$ & $1.770 \times 10^{-4}$ \\
\hline$A_{0}$ & $-1.336 \times 10^{-8}$ & $1.787 \times 10^{-7}$ \\
\hline
\end{tabular}

The table shows that some of the coefficients are very small and consequently they could be possibly neglected for the control system design.

\section{Poles and zeros}

Poles $p_{i}$ of a system are defined as roots of the transfer function denominator whereas zeros $z_{i}$ are given by the numerator roots. Given the range of coefficients from the Table 1 , it is possible to compute also the range of poles and zeros of $G_{T / \dot{m}_{F K}}$. Results are summarized in

Table 2 where the roots are divided into their real and imaginary parts for the case they are complex.

Table 2: Range of $G_{T / \dot{m}_{F K}}$ Poles $p_{i}$ and Zeros $z_{i}$

\begin{tabular}{|c|c|c|c|c|}
\hline$z_{i} / p_{i}$ & Real min. & Real max. & $\begin{array}{c}\text { Imag. } \\
\text { min. }\end{array}$ & $\begin{array}{c}\text { Imag. } \\
\text { max. }\end{array}$ \\
\hline$z_{1}$ & 0.0185 & 0.1601 & 0 & 0 \\
\hline$z_{2}$ & -0.0062 & -0.0062 & 0 & 0 \\
\hline$z_{3}$ & $-1.973 \times 10^{-5}$ & 0.0016 & 0 & 0 \\
\hline$p_{1}$ & 0 & 0 & 0 & 0 \\
\hline$p_{2}$ & -0.0226 & -0.0059 & 0 & $\begin{array}{c}5.590 \\
\times 10^{-4}\end{array}$ \\
\hline$p_{3}$ & -0.0067 & 0.0021 & $\begin{array}{c}-5.590 \\
\times 10^{-4}\end{array}$ & $\begin{array}{c}9.108 \\
\times 10^{-4}\end{array}$ \\
\hline$p_{4}$ & -0.0018 & $8.464 \times 10^{-4}$ & $\begin{array}{c}-9.108 \\
\times 10^{-4}\end{array}$ & 0 \\
\hline
\end{tabular}

Zeros at (or very close to) the origin indicate derivative behaviour whereas poles at the same position signalize integrative properties. The table shows that one pole $\left(p_{1}\right)$ is directly at the origin resulting in integrative behaviour of the temperature $T(t)$ with respect to $\dot{m}_{F K}(t)$. If the poles are located in the left part of the complex plane (their real parts are negative), the system is stable. From this point of view the table shows that generally the system embodies also instability. In addition, when the poles are complex (they also have imaginary parts), it indicates oscillatory behaviour. As revealed by the table, in some conditions the system may embody oscillatory behaviour, however absolute values of complex parts of the poles are relatively small which shows that this effect is not so significant. From the results, it can be also deduced that the system possesses non-minimum phase (NMP) behaviour some of the zeros may become positive (unstable). Generally, NMP-systems are more difficult to control. Having the range of poles, it would be also possible to compute the range of time-constants and of the gain for the system. Although this information would be also interesting from the controller design point of view, due to the limited space it is not provided.

\section{Discussion}

The computed range of $G_{T / \dot{m}_{F K}}$ coefficients from Table 1 shows that for the control design, some of the coefficients could be neglected (e.g. $B_{0}$, possibly also $\left.B_{1}, A_{0}\right)$. Consequently, the linear time-variant model will be of a simpler form, which is useful.

\section{Suggested control strategies}

Havig the approximate uncertainty intervals of the $G_{T / \dot{m}_{F K}}$ coefficients, it suggests using the robust control approach (e.g. Morari and Zafirou 1989). As parameters of the linearized model change, an alternative idea could also be the usage of adaptive control strategies (e.g. Åström and Wittenmark 1989). Another possible approach which proved to be successful is the predictive control (Srinivasan and Bonvin 2007, Sámek and Macků 2007). At present, the system is controlled only as a Single Input - Single Output (the temperature inside the reactor is controlled only by means of the chromium sludge input flow rate). It would be useful to include also the coolant flow rate $\dot{m}_{v}(t)$ as a manipulated variable and use the MIMO control design strategies (e.g. Skogestad and Postlethwaite 1996).

\section{CONCLUSION}

This contribution was focused on the analysis of a reactor used for the tanning waste recovery. The analysis was made by both theoretical and simulation means in order to provide useful information for optimal controller design. The nonlinear model of the system was derived and transformed into a linear timevariant system which was used for further investigation of the process properties. The range of transfer function coefficients was determined and possible control strategies were outlined. In this work, the main focus was on the relationship between the controlled variable - temperature inside the reactor and the manipulated variable given by the chromium sludge input flow rate. From the controller design point of view, it would be useful to investigate also the relationship between the second practically possible manipulated variable - the coolant mass flow rate and the temperature. 


\section{ACKNOWLEDGEMENTS}

The work was supported by the Grant Agency of the Czech Republic under the grant no. 102/07/P148 and by the Ministry of Education of the Czech Republic under the grant no. MSM 7088352102. Authors are also grateful to Dr. Chalupa for the refinement of the presented mathematical model.

\section{APENDIX}

Formulas for coefficients of the linear time-variant model

$$
\begin{gathered}
a_{21}(t)=-\frac{\dot{m}_{F K}(t)}{m^{2}(t)}\left(1-a_{F K}(t)\right), a_{22}(t)=-\frac{\dot{m}_{F K}(t)}{m(t)}-A e^{-\frac{E}{R T(t)}} \\
a_{23}(t)=-A e^{-\frac{E}{R T(t)}}\left(\frac{E}{R T^{2}(t)}\right) a_{F K}(t) \\
a_{31}(t)=-\frac{1}{m^{2}(t) c_{R}}\left[\dot{m}_{F K}(t)\left(c_{F K} T_{F K}(t)-c_{R} T(t)\right)+K S\left(T_{v}(t)-T(t)\right)\right] \\
a_{32}(t)=\frac{A e^{-\frac{E}{R T(t)}} \Delta H_{r}}{c_{R}}, a_{34}(t)=\frac{K S}{m(t) c_{R}} \\
a_{33}(t)=\frac{A \Delta H_{r} E a_{F K}(t)}{R T^{2}(t) c_{R}} e^{-\frac{E}{R T(t)}}-\frac{K S}{m(t) c_{R}}-\frac{\dot{m}_{F K}(t)}{m(t)} \\
a_{43}=\frac{K S}{m_{v R} c_{v}}, a_{44}(t)=-\frac{1}{m_{v R}}\left(\dot{m}_{v}(t)+\frac{K S}{c_{v}}\right) \\
b_{21}(t)=\frac{1-a_{F K}(t)}{m(t)}, b_{31}(t)=\frac{1}{m(t)}\left(\frac{c_{F K} T_{F K}(t)}{c_{R}}-T(t)\right) \\
b_{33}(t)=\frac{\dot{m}_{F K}(t) c_{F K}}{m(t) c_{R}}, b_{42}(t)=\frac{1}{m_{v R}}\left(T_{v p}(t)-T_{v}(t)\right) \\
b_{44}(t)=\frac{\dot{m}_{v}(t)}{m_{v R}}
\end{gathered}
$$

\section{Formulas for transfer function coefficients}

$$
\begin{aligned}
& B_{3}(t)=b_{31}(t) \\
& B_{2}(t)=a_{32}(t) b_{21}(t)-b_{31}(t) a_{22}(t)+a_{31}(t)-a_{44}(t) b_{31}(t) \\
& B_{1}(t)=a_{21}(t) a_{32}(t)-a_{31}(t) a_{22}(t)-\cdots \\
& \cdots-a_{44}(t)\left[a_{32}(t) b_{21}(t)-b_{31}(t) a_{22}(t)+a_{31}(t)\right] \\
& B_{0}(t)=-a_{44}(t)\left[a_{21}(t) a_{32}(t)-a_{31}(t) a_{22}(t)\right] \\
& A_{2}(t)=-a_{44}(t)-a_{22}(t)-a_{33}(t) \\
& A_{1}(t)=a_{22}(t) a_{44}(t)-a_{34}(t) a_{43}-a_{32}(t) a_{23}(t)+\cdots \\
& \cdots+a_{33}(t) a_{44}(t)+a_{22}(t) a_{33}(t) \\
& A_{0}=-a_{22}(t) a_{33}(t) a_{44}(t)+a_{22}(t) a_{34}(t) a_{43}+\cdots \\
& \cdots+a_{32}(t) a_{23}(t) a_{44}(t)
\end{aligned}
$$

\section{REFERENCES}

Aloy, M. and B. Vulliermet. 1998. "Membrane technologies for the treatment of tannery residual floats." Journal of the
Society of Leather Technologies \& Chemists 82, No.4 (JulAug), 140-142.

Åström, K.J. and B. Wittenmark. 1989. Adaptive Control. Addison-Wesley, Reading, MA.

Cabeza, L.F., Taylor, M.M., Dimaio, G.L., Brown, E.M., Mermer, W.N., Carrio, R., Celma, P.J. and J. Cot. 1998. "Processing of leather waste: pilot scale studies on chrome shavings. Isolation of potentially valuable protein products and chromium." Waste Management 18, No.3, 211-218.

Kolomazník, K., Mládek, M., Langmaier, F., Taylor, M., Diefendorf, E.J., Marmer, W.N., Brown, E. M. and L. Tribula. 1996. CR Patent 280 655, Czech Republic (Feb).

Macků, L. 2004. "Control design for the preparation of regenerate for tanning". Ph.D. thesis. Tomas Bata University in Zlín, Czech Republic (in Czech).

Macků, L. 2005. "Modeling of tanning salts regeneration process." In Proceedings of the $15^{\text {th }}$ Int. Conf. Process Control 2005 (High Tatras, Slovakia, Jun.7-10). Bratislava: Slovak University of Technology, 127/1$127 / 4$.

Morari, M. and E. Zafirou. 1989. Robust Process Control. Prentice Hall, Englewood Cliffs, New Jersey.

Sámek, D. and L. Macků. 2007. "Simulation of model predictive control of semi-batch reactor." In Proc. Int. Symp. on Systems Theory SINTES 13 (Craiova, Romania, Oct.18-20). Craiova: University of Craiova, 180-185.

Skogestad, S. and I. Postlethwaite. 1996. Multivariable Feedback Control: Analysis and Design. John Wiley \& Sons, Chichester, England.

Srinivasan, B. and D. Bonvin. 2007. "Controllability and stability of repetitive batch processes." Journal of Process Control 17, 285-295.

Tiravanti, G., D. Petruzzelli and R. Passino. 1996. "Low and non waste technologies for metals recovery by reactive polymers." Waste Management 16, No.7, 597-605.

Tiravanti, G., D. Petruzzelli and R. Passino. 1997. "Pretreatment of tannery wastewaters by an ion exchange process for Cr(III) removal and recovery." Water Science and Technology 36, No.2-3, 197-207.

\section{AUTHOR BIOGRAPHIES}

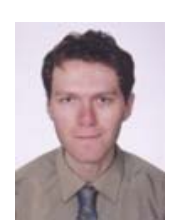

FRANTIŠEK GAZDOŠ was born in Zlín, Czech Republic, and graduated from the Technical University of Brno in 1999 with MSc. degree in Automation. He then followed studies of Technical cybernetics at Tomas Bata University in Zlín, obtaining Ph.D. degree in 2004. Now he works as a senior lecturer in the Department of Process Control, Faculty of Applied Informatics of the same University. E-mail: gazdos@fai.utb.cz.

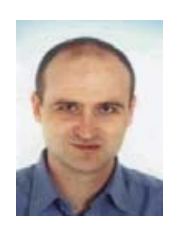

LUBOMÍR MACKŮ was born in Uherské Hradiště, Czech Republic and graduated from the Technical University of Brno in 1996 with MSc. degree in Process Control Engineering. He followed studies of Technical cybernetics at Tomas Bata University in Zlín, obtaining Ph.D. degree in 2004. Now he woks as a senior lecturer in the Department of Electrotechnics and Measurements, Faculty of Applied Informatics of the same University. E-mail:macku@fai.utb.cz. 